\title{
The Bibliometric Analysis of Autonomous Learning Studies in China WANG Lina
}

\author{
Shanghai Medical Instrumentation College, USST, Shanghai, 200093
}

\begin{abstract}
This study retrievals papers on autonomous learning published in 14 key foreign linguistics journals ${ }^{1}$ from 1998 to 2012 in CNKI. By using bibliometric method, it conducted a statistical analysis of papers on autonomous learning in three aspects: research contents, research methods and subjects. The analysis reveals that China has made certain progress in the filed of autonomous learning research during 15 years. The number of published papers has been increasing. The research contents are increasingly comprehensive. Moreover, the research methods and subjects are gradually diversified. However, there are still some problems. The research contents are over concentrated with less innovative perspectives. The subjects are unbalanced and the empirical research methods need to be strengthened. On this basis, suggestions on future studies are proposed.
\end{abstract}

Keywords: autonomous learning; CNKI; bibliometrics

\footnotetext{
${ }^{1}$ These 14 key foreign linguistics journals are Foreign Language Teaching Abroad/Foreign Language Learning Theory and Practice, Journal of PLA University of Foreign Languages, Shandong Foreign Language Teaching Journal, Journal of Sichuan International Studies University, Journal of Foreign Languages, Computer-assisted Foreign Language Education, Foreign Language Education, Foreign language Teaching and Research, Foreign Language World, Foreign Language Research, Foreign Languages Research, Foreign Languages and Their Teaching, Modern Foreign Languages and Foreign Languages in China.
}

(C) 2013. The authors - Published by Atlantis Press

\section{Introduction}

Autonomous learning is an important research topic of education psychology. This concept originates from some debates about how to cultivate lifelong learning ability and independent thinking ability in western education field in 1950s. Henri Holec brought this concept into the field of foreign language teaching for the first time. Holec (1981) thought that autonomy is the ability to take charge of one's own learning. Since then, autonomous learning has been a topic of widespread discussion. Numerous scholars published books and papers on autonomous learning. They discussed the theoretical background of autonomous learning from different perspectives and gave definitions (Zimmerman \& Pons, 1986; Allwright, 1990; Little, 1991; Dickinson, 1995; Benson, 2001). Some scholars discussed factors that influence on autonomous learning (Nunan, 1997; Dickinson, 1992; Hedge, 2000; Egel, 2009). Some scholars explained and analyzed application strategies, curriculum and practice results of foreign languages autonomous learning cultivation (Wenden, 1991; Benson \& Voller, 1997; Cotterall, 2000). Other scholars developed autonomous learning scales ( Lindner et al., 1996; Everson et al., 1997) .

Studies of autonomous learning in Chinese foreign language teaching circles began in 1990s. Based on bibliometric method, this paper analyzes autonomous learning studies in China from 1998 to 2012. It conducted a statistical analysis of 
autonomous learning papers in three aspects: research contents, research methods and subjects.

\section{Sample}

This paper selected CNKI USST (University of Shanghai Science and Technology) as its data source. It retrieved papers from 14 key foreign linguistics journals (Standard of Beijing University 2011) from 1998 to 2012, with autonomous learning as title. A total of 157 papers were retrieved. After removing the nonacademic papers, the remaining 148 papers were used for bibliometric analysis.

\section{Results}

\subsection{Statistical analysis of research contents}

In the statistical analysis of research contents, this study took autonomous learning as topic of related papers. Then it classified the 148 papers according to their subtopics and divided them into 9 subtopics (see table 1). For papers with more than one subtopic, the most im- portant subtopic was chosen as its final subtopic during statistics process.

Studies on research focuses can reflect the concern degree of academic circles on certain topics or areas in a certain period of time. This paper draws on the method of Zhang Wei (2006) to decide research focuses. It measures research focuses with the total of average growth rate ranking $(\mathrm{R})$, growth quantity ranking $(\mathrm{Q})$ and average total number ranking $(\mathrm{T})$ of papers published in a certain filed. The research focuses are evaluated according to the weighted mean of these three indicators' rankings. Then, they are ordered based on the evaluation results. The measurement equation is: research focus $=$ $(\mathrm{T}+\mathrm{Q}+\mathrm{R}) / 3$

Average total number $=($ the total of papers in all years)/number of years

Average growth quantity $=$ AVERAGE (paper number of the current year-paper number of last year)

Average growth rate $=$ AVERAGE (growth quantity of the current year/paper number of last year).

Table 1 shows the statistical results of research focuses of papers on autonomous learning.

Table 1 Statistical results of research focuses

\begin{tabular}{|c|c|c|c|c|c|c|c|}
\hline Subtopics.r & $\begin{array}{l}\text { Research } \\
\text { focuses } \\
\text { ranking.1 }\end{array}$ & $\begin{array}{l}\text { Average } \\
\text { total } \\
\text { number., }\end{array}$ & $\begin{array}{l}\text { Average } \\
\text { growth } \\
\text { quantity. }\end{array}$ & $\begin{array}{l}\text { Average } \\
\text { growth } \\
\text { rate } \\
(\%) .\end{array}$ & $\begin{array}{l}\text { Average } \\
\text { total } \\
\text { number } \\
\text { ranking. }\end{array}$ & $\begin{array}{l}\text { Average } \\
\text { growth } \\
\text { quantity } \\
\text { ranking, }\end{array}$ & $\begin{array}{l}\text { Average } \\
\text { growth } \\
\text { rate } \\
\text { ranking. }\end{array}$ \\
\hline $\begin{array}{l}\text { Autonomous leaming abil- } \\
\text { ity cultivation.t }\end{array}$ & 1.1 & 2.80 & 0.29. & 74.80. & 1. & 1.1 & 1. \\
\hline $\begin{array}{l}\text { Information technology } \\
\text { and auton omous learning. }\end{array}$ & 2.1 & 1.73 .1 & 0.14 .7 & 35.24. & 2.1 & 2.1 & 2.1 \\
\hline $\begin{array}{l}\text { Survey of autonomous } \\
\text { learning.r }\end{array}$ & 3.1 & 1.07 .1 & 0.14 .1 & 34.52 .1 & 4.1 & 2.1 & 3.1 \\
\hline $\begin{array}{l}\text { Discussion of theories and } \\
\text { introduction of related } \\
\text { researches abroad, }\end{array}$ & 4.1 & 1.13. & 0.14. & 22.62. & 3. & 2.1 & 5.1 \\
\hline $\begin{array}{l}\text { Influencing factors of all- } \\
\text { tonomous learning. }\end{array}$ & 5.1 & 1.07 .7 & 0.07. & 30.36. & 4. & 5.1 & 4.1 \\
\hline $\begin{array}{l}\text { Autonomous learning in } \\
\text { different aspects of Eng- } \\
\text { lish learning. }\end{array}$ & 6.1 & 1.07 .1 & 0.07 & 22.62 .1 & 4.1 & 5.1 & 5.1 \\
\hline $\begin{array}{l}\text { Teachers' role in autono- } \\
\text { mous learning, }\end{array}$ & 7.1 & 0.47 .1 & 0.00. & 10.71 & 7.1 & 7.1 & 7.1 \\
\hline The others.1 & 8. & 0.33. & 0.00 & 7.14 & 8. & 7. & 8.7 \\
\hline $\begin{array}{l}\text { Culture suitability of an- } \\
\text { tonomous learning, }\end{array}$ & 9. & 0.20 & 0.00 & 0.00 & 9. & 7.8 & 9.1 \\
\hline
\end{tabular}

Note: The others are subtopics which cannot be covered by the other eight subtopics. 
From table 1, it can be seen that, firstly, during 15 years, subtopic autonomous learning ability cultivation ranks first in the research focuses of papers on autonomous learning in China. Its average total number of published papers each year is 2.80 , the average growth quantity of published papers each year is 0.29 , the average growth rate of published papers each year is $74.80 \%$. They all rank first. Secondly, subtopic information technology and autonomous learning ranks second. Its average total number of published papers each year is 1.73 , average growth quantity of published papers each year is 0.14 , and average growth rate of published papers each year is $35.24 \%$. They all rank second. Thirdly, subtopics survey of autonomous learning, discussion of theories and introduction of related researches abroad, influencing factors of autonomous learning and autonomous learning in different aspects of English learning rank third, fourth, fifth and sixth respectively. Fourthly, subtopics teachers' role in autonomous learning, the others and culture suitability of autonomous learning rank seventh, eighth and ninth respectively. Their average growth quantity is all 0 .

After identifying the research focuses of autonomous learning in China, we studied on the specific contents of each subtopic. For autonomous learning ability cultivation, the main specific contents are discussion of necessity and feasibility of cultivating learner autonomy in China, autonomous learning ability cultivation by strategy training, integrated application of autonomous learning mode and classroom-teaching mode, autonomous learning awareness and so on (see Wei Yuyan, 2002; Sun Bingtan, 2008; Zhang Yanjun, 2004). For information technology and autonomous learning, the main specific contents are English learning websites and autonomous learning, measures to cultivate and develop auton- omous learning in computer and internet aided foreign language education, development and application of autonomous learning corpus (see Fu Lingfang \& Yang Jianding, 2007; Jiang Liping, 2006; Liang Hongmei et al., 2005). For survey of autonomous learning, the main research contents are investigation of autonomous learning beliefs, autonomous learning overall tendency investigation, comparative study of students' autonomous learning ability (see Zhang Qingyun, 2012; Li Xiuping, 2006). For discussion of theories and introduction of related researches abroad, the main contents are discussions of autonomous learning connotation, main modern learning approaches' influence on the concept of autonomous learning, introduction of autonomous learning centers abroad (see Qi Hongbo, 2002; Guo Li, 2000; Hua Weifen, 2001; 2003). For influencing factors of autonomous learning, factors such as beliefs, motivation, self-efficacy, attribution, learning strategies are discussed (see Li Kun \& Yu Liming, 2008; Lei Xiao, 2005; Zhang Dianyu, 2005). For autonomous learning in different aspects of English learning, they are teaching of English vocabulary, English phoneme, listening, reading, writing, translation and interpretation (see Chu Xiangqun \& Liu Caimin, 2007; Xiao Jing \& Zuo Niannian, 2006; Liu Ping, 2009; Wang Zheng \& Sun Dongyun, 2009; Wang Yi \& Xuan An, 2012; Liu Menglian, 2011). For teachers' role in autonomous learning, they are discussions on the roles that teacher have in autonomous learning in details (see Tan Hong, 2001; Cao Qunying, 2009; Jiang Qingxin, 2006). There are 5 papers in all for the other subtopics (see Hu Jiehui, 2011; Gao Jili \& Li Xiuping, 2011; Yang Hong, 2009; Zhang Chun, 2008; Sun Hong, 2004). For culture suitability of autonomous learning, they are studies of culture suitability of autonomous learning in cross-culture communication and rela- 
tionship between autonomous learning and social cultural environment (see Qi Hongbo, 2004; Hao Qinhai, 2005).

\subsection{Statistical analysis of research methods}

According to research methods of applied linguistics classified by Gao Yihong et al. (1999) and empirical study methods classified by Lin Zhengjun et al. (2009), we classified research methods of autonomous learning into two types: (1) Literature researches. They include discussions of theoretical issues with speculative method and its significance to teaching, operation description and evaluation of specific teaching steps, summary of personal experience and personal views to certain issues. (2) Empirical researches. They include three sub-types, qualitative researches, quantitative researches and comprehensive researches. Qualitative researches are case studies based on filed recording or recording transcription materials. Quantitative researches are studies based on statistical data. It is further divided into experimental quantitative researches and non-experimental quantitative researches. Comprehensive researches are researches combining qualitative and quantitative researches.

According to the above research methods classification, we did statistical analyses of 148 papers on autonomous learning. Table 2 shows the results.

Table 2 Statistical results of research methods

\begin{tabular}{|c|c|c|c|c|c|}
\hline \multirow{3}{*}{$\begin{array}{l}\text { mexhods } \\
\text { year }\end{array}$} & \multirow{3}{*}{$\begin{array}{l}\text { Literature } \\
\text { researches }\end{array}$} & \multicolumn{4}{|c|}{ Empirical researches } \\
\hline & & \multirow{2}{*}{$\begin{array}{l}\text { Qualitative } \\
\text { researches }\end{array}$} & \multicolumn{2}{|c|}{ Quantitative researches } & \multirow{2}{*}{$\begin{array}{l}\text { Comprehensive } \\
\text { researches }\end{array}$} \\
\hline & & & experimental & Non-experimental & \\
\hline 2012 & 7 & 1 & 0 & 1 & 4 \\
\hline 2011 & 4 & 0 & 2 & 3 & 6 \\
\hline 2010 & 2 & 0 & 1 & 1 & 5 \\
\hline 2009 & 4 & 0 & 1 & 4 & 8 \\
\hline 2008 & 6 & 0 & 0 & 1 & 8 \\
\hline 2007 & 6 & 1 & 5 & 1 & 4 \\
\hline 2006 & 9 & 2 & 1 & 1 & 4 \\
\hline 2005 & 7 & 0 & 0 & 0 & 7 \\
\hline 2004 & 8 & 0 & 1 & 2 & 3 \\
\hline 2003 & 2 & 0 & 0 & 1 & 0 \\
\hline 2002 & 6 & 0 & 1 & 0 & 1 \\
\hline 2001 & 4 & 0 & 0 & 0 & 0 \\
\hline 2000 & 1 & 0 & 0 & 0 & 0 \\
\hline 1999 & 0 & 0 & 0 & 0 & 0 \\
\hline 1998 & 1 & 0 & 0 & 0 & 0 \\
\hline total & 67 & 4 & 12 & 15 & 50 \\
\hline percentage $(\%)$ & 45 & 3 & 8 & 10 & 34 \\
\hline
\end{tabular}

From table 2 we can see that, firstly, papers on autonomous learning are mainly empirical researches. There are totally 81 papers adopting this research method (accounting for 55\%). Among them, 50 papers are comprehensive researches (accounting for $34 \%$ ). 27 papers are quantitative researches, with 12 experimental quantitative research (accounting for 8\%), 15 non-experimental quantitative researches (accounting for 10\%). The least adopted methods in empirical studies are qualitative researches, four papers in all (accounting for 3\%). Secondly, there are 67 literature researches on autonomous learning (accounting for $45 \%$ ).

\subsection{Statistical analyses of subjects}

After excluding 30 papers whose subjects are not clearly defined, this paper ana- 
lyzed subjects of the left 118 papers. The

statistical results are shown in table 3.

Table 3 Statistical results of subjects

\begin{tabular}{|c|c|c|c|}
\hline \multicolumn{3}{|l|}{ Subjects } & Number of Papers \\
\hline \multirow{3}{*}{ college students } & \multicolumn{2}{|c|}{ students of higher vocational colleges } & 2 \\
\hline & \multirow{2}{*}{ undergraduates } & non-English major & 83 \\
\hline & & English major & 15 \\
\hline graduates & \multicolumn{2}{|c|}{ master's degree graduates } & 7 \\
\hline high school students & \multicolumn{2}{|c|}{ junior high school students and senior high school students } & 2 \\
\hline \multirow{3}{*}{ mixed groups } & \multicolumn{2}{|c|}{$\begin{array}{l}\text { non-English major undergraduates + English major under- } \\
\text { graduates }\end{array}$} & 5 \\
\hline & \multicolumn{2}{|c|}{ undergraduates + students of higher vocational colleges } & 1 \\
\hline & \multicolumn{2}{|c|}{$\begin{array}{l}\text { undergraduates + master's degree graduates +doctor's de- } \\
\text { gree graduates }\end{array}$} & 1 \\
\hline other & \multicolumn{2}{|c|}{$\begin{array}{l}\text { adult English learners (non-academic education); Chinese } \\
\text { and western European students learning English in the UK }\end{array}$} & 2 \\
\hline
\end{tabular}

From table 3, we can see that subjects of 83 papers on autonomous learning are non-English major undergraduates. Subjects of 15 papers are English major undergraduates. There are 7 papers whose subjects are master's degree graduates. Whose subjects are students of higher vocational colleges and high school students are respectively 2 papers. 7 papers' subjects are mixed group. Among them, there are 5 papers whose subjects are non-English major and English major undergraduates. There is 1 paper whose subjects are undergraduates and students of higher vocational colleges. There is also 1 paper whose subjects are undergraduates, master's degree graduates and doctor's degree graduates. Moreover, there is respectively 1 paper whose subjects are adult English learners (non academic education) and Chinese and western European students learning English in the UK.

In conclusion, firstly, subjects of autonomous learning papers have a wide coverage. They are high school students (see Geng Fei, 2012), students of higher vocational colleges (see Zhao Jizheng, 2008), undergraduates, master's degree graduates (see Li Lin \& Gao Peng, 2007), doctor's degree graduates (see Liu Wenyu \& Cha Jian, 2012) and so on. Secondly, the subjects of papers on autonomous learning are mainly nonEnglish major undergraduates (see Zhang
Qingyun, 2012), followed by English major undergraduates (see Liu Jinxia, 2009; Li Xiuping, 2006).

\section{Discussion}

By statistical analyses of papers on autonomous learning in China, we found three problems deserving our attentions.

Firstly, research contents of autonomous learning are over concentrated with less innovative perspectives. For subtopics of autonomous learning, most papers are about discussions of autonomous learning ability cultivation. This may be caused because that most scholars think that autonomous learning researches should meet the needs of English teaching in China, and ultimately find effective methods to cultivate students' autonomous learning ability. There are going to be more and more researches on autonomous learning in the future. We call for domestic scholars' more innovative perspectives of autonomous learning, combining the actual situation of English teaching in China.

Secondly, empirical methods of autonomous learning studies should be strengthened. From statistical analyses, we can see that autonomous learning studies in China are mainly empirical researches. This finding is different from the other scholar (Gao Jili, 2006), who 
thinks that studies of autonomous learning in China lack of empirical researches. This may be caused by different statistical periods. Gao covers papers before 2004. In recent years, empirical researches draw more and more attention in applied linguistics. And researches on autonomous learning are no exception.

On the one hand, we should see that there are more and more empirical researches of autonomous learning. On the other hand, we find that the specific empirical methods are relatively simple, mostly simple quantitative statistics which describe the correlation of variables but rarely involve analysis of the casual relationship of variables, for example, studies of influencing factors of autonomous learning. Studies of autonomous learning antecedents can be carried on to identify its influencing factors and further explore their influencing paths. Moreover, it is worth mentioning that there are the least qualitative researches in the empirical studies of autonomous learning (4 papers in all, only accounting for $3 \%$ ). Though qualitative methods are also employed in comprehensive researches, most of them are interviews. Only a minority of papers adopt learning records, diaries, portfolios, reports, classroom observation, and case studies. Data from qualitative methods such as classroom observation are important too for autonomous learning researches. We look forward to comprehensive qualitative studies in the future empirical researches on autonomous learning.

Thirdly, subjects of autonomous learning are unbalanced. From statistical analyses we can see that subjects of more than half papers on autonomous learning are non-English major undergraduates. This is mainly because of the great proportion of non-English major undergraduates among English learners in China. However, we cannot neglect studies of other subjects, for example, students of higher vocational colleges, adult English learners (non-academic education). It is widely believed that autonomous learning ability of students of higher vocational colleges is not as good as the one of undergraduates or graduates. Moreover, their English learning content and environment are greatly different from the ones of other students. Therefore, studies of this group of English learners should be strengthened. Moreover, attention should also be paid to adult English learners (non-academic education). In China, there is a large group of adult English learners of non-academic education. Studies of their autonomous learning are important too. Unfortunately, they have until now not received sufficient research attention.

\section{Conclusion}

This study analyzes 148 papers on autonomous learning published in 14 key foreign linguistics journals from 1998 to 2012 in CNKI. During 15 years, Chinese academics in foreign language teaching circle have done useful explorations of autonomous learning. Published papers on autonomous learning have been increasing in number. The research contents are more and more comprehensive. Subjects and methods are more and more diversified.

Researches on autonomous learning have great practical significance to college English teaching reform in China. On the one hand, we should see the progress we have made in autonomous learning studies. On the other hand, we should address properly the existing problems in autonomous learning in the future studies.

\section{Acknowledgements}

This paper is supported by Innovation Program of Shanghai Municipal Education Commission. 


\section{References}

[1] Allwright, D. Autonomy in language pedagogy [A]. CRILE Working Paper 6. Center for Research in Education [C]. University of Lancaster, 1990.

[2] Benson, P. Teaching and Researching Autonomy in Language Learning [M]. Harlow: Pearson Education Limited, 2001.

[3] Benson, P. \& P. Voller (eds). Autonomy and Independence in Language Learning [M]. London: Longman, 1997.

[4] Cotterall, S. Promoting learner autonomy through the curriculum: Principles for designing language courses [J]. ELT Journal, 2000.

[5] Dickinson, L. Autonomy and motivation: a literature review [J]. System, 1995.

[6] Dickinson, L. Learner Training for Language Learning [M]. Dublin: Authentik, 1992.

[7] Egel, I. P. Learner autonomy in the language classroom: From teacher dependency to learner independency [J]. Procedia Social and Behavioral Sciences, 2009.

[8] Everson, H. T., Tobias, S. \& Laitusis, V. Do Metacognitive Skills and Learning Strategies Transfer across Domains? [R]. Chicago: The Symposium on "Assessing Metacognitive Knowledge Monitoring", The Annual Convention of the American Educational Research Association, 1997.

[9] Gao Jili. Retrospection and prospect of studies on learner autonomy in China [J]. Foreign Language Teaching Abroad, 2006(2).

[10] Gao Yihong, Li Lichun \& Lv Jun. Trends of research methods of applied linguistics in China and the West [J]. Foreign language Teaching and Research, 1999(2).

[11] Hedge, T. Teaching and Learning in the Language Classroom [M]. Oxford: Oxford University Press, 2000.
[12] Holec, H. Autonomy and Foreign Language Learning [M]. Oxford: Pergamon Press, 1981.

[13] Lindner, R. W., Harris, B. R. \& Gordon, W. I. The Design and Development of the Self-regulated Learning Inventory: A Status Report [R]. New York: The Annual Convention of the American Educational Research Association, 1996.

[14] Lin Zhengjun, Liu Yongbing \& Wang Bing. Present situation and prospect of English classroom discourse studies in China [J], Journal of $X i$ 'an International Studies University, 2009(1).

[15] Liu Menglian. On the theoretical model of computer assisted interpreter self-training [J]. Computer-assisted Foreign Language Education, 2011 (5).

[16] Little, D. Learner Autonomy: Definitions, Issues and Problems [M]. Dublin: Authentik, 1991.

[17] Nunan, D. Designing and adapting materials to encourage learner autonomy [A]. In Benson P \& Voller P (eds.). Autonomy and Independence in Language Learning [C]. London: Longman, 1997.

[18] Wenden, A. L. Learner Strategies for Learner Autonomy: Planning and Implementing Learner Training for Language Learners [M]. Hertfordshire, UK: Prentice-Hall International, 1991.

[19]Zhang Qingyun. An investigation into non-English majors' beliefs about learner autonomy [J]. Shandong Foreign Language Teaching Journal, 2012(1).

[20]Zhang Wei et al. Comparison of hot areas of business administration research between the foreign and the domestic based on literature metrology [J]. Science of Science and Management of $S \& T, 2006(3)$. 